\title{
LUGARES HABITADOS
}

\section{INHABITED PLACES}

\section{De pacientes a discentes: mujeres en la producción autogestionaria del hábitat}

\section{Women and self-managed habitat production}

\author{
María Carla Rodríguez $^{* *}$ y María Soledad Arqueros Mejica**
}

Citar este artículo como: Rodríguez, M.C. y Arqueros Mejica, M. S. (2020). De pacientes a discentes*: mujeres en la producción autogestionaria del hábitat. Revista Nodo, 14(28), pp. 58-73

\section{Resumen}

En este artículo indagamos en las prácticas autogestionarias de producción del hábitat a la luz de los cambios producidos en la vida de las mujeres. Para ello recuperamos la experiencia de las cooperativas La Fábrica y El Molino, del Movimiento de Ocupantes e Inquilinos de la ciudad de Buenos Aires, Argentina. El análisis se sostiene en un trabajo de campo que se nutre de observación participante, entrevistas etnográficas y una encuesta específica realizada en 2018. A lo largo del escrito, se ponen de relieve los diversos modos en que la participación de las mujeres en instancias colectivas de toma de decisiones significativas sobre su hábitat a través de la autogestión, incide en las subjetividades. Concluimos que ese proceso habilita tendencias de despatriarcalización como parte de la resignificación de la vida cotidiana y asociadas con una puesta en valor de lo colectivo y lo "común".

Palabras clave: relaciones de género, mujeres, ciudad, producción autogestionaria del hábitat, patriarcado.

\section{Abstract}

In this paper, we explore the relationship between self-managed habitat production and changes in women's life. Our study is based on the experience of the cooperatives "La Fábrica" and "El Molino" cooperatives, of the Movement of Occupants and Tenants of the city of Buenos Aires Argentina. The analysis is based on fieldwork-based on participant observation, ethnographic interviews, and a specific survey conducted in 2018. Throughout the paper, the various ways in which the participation of women in collective decision-making bodies that have a significant impact on their habitat through self-management are highlighted. We conclude that this process enables tendencies of delocalization as part of the resignation of daily life and associated with a value of the collective and the "common".

Keywords: gender relationships, women, city, selfmanagement urbanism, patriarchy.

\section{Fecha de recepción: 15 de junio de 2019 • Fecha de aceptación: 15 de octubre de 2019}

\footnotetext{
* Neologismo introducido por Paulo Freire para aludir al proceso de aprendizaje basado en la circulación dialógica de la palabra que habilita el pensar y hacer "acertadamente" con capacidad de reflexión crítica sobre su práctica y el conjunto.

*: Doctora en Ciencias Sociales. Universidad de Buenos Aires, Facultad de Ciencias Sociales, Instituto de Investigaciones Gino Germani. CONICET. Buenos Aires, Argentina. E-mail: trebol1968@gmail.com

***: Doctora en Ciencias Sociales. Universidad de Buenos Aires, Facultad de Ciencias Sociales, Instituto de Investigaciones Gino Germani. CONICET. Departamento de Ambiente y Turismo, Universidad Nacional de Avellaneda. Buenos Aires, Argentina. E-mail: soledad.arqueros@gmail.com
} 


\section{Introducción}

Este artículo indaga en las prácticas autogestionarias de producción del hábitat ${ }^{1}$ a la luz de los cambios producidos en la vida de las mujeres involucradas. La producción autogestionaria del hábitat se caracteriza por la puesta en marcha de procesos colectivos de toma de decisiones y disputa por la orientación de recursos e institucionalidades estatales (suelo, normas, políticas y programas, entre otras), que son laboriosa y creativamente redirigidos por sus participantes/productores para abordar la resolución de temáticas significativas de la vida. Protagonizados mayoritariamente por mujeres que se involucran a partir de sentirse interpeladas en sus roles tradicionales de madres y cuidadoras, estos procesos involucran a sus participantes en acciones comunes co-creadoras de nuevas sociabilidades, que resignifican e interpelan sus trayectorias biográficas previas y comienzan a horadar las categorías binarias (Soto Villagrán, 2016; Butler, 2006) que constituyen claves organizadoras del sentido común hegemónico.

Situadas en el contexto actual de neoliberalismo urbano de la ciudad de Buenos Aires, nuestra hipótesis es que en los procesos de autogestión del hábitat se invisten y negocian posiciones de género ${ }^{2}$ que tienden a producir cambios en la subjetividad y, desde ese lugar, aportan a un proceso de despatriarcalización que se desarrolla junto con el despliegue de prácticas desmercantilizadoras de producción del hábitat que recuperan la ciudad como socialmente producida (entre ellas, la ayuda mutua y la propiedad colectiva). En base a Bonder (1999), entendemos el proceso de subjetivación en términos de una trama de posiciones del sujeto, que se inscribe en variables relaciones de fuerza en

1 Con base en Yujnovsky (1984), entendemos que el hábitat comprende, además de la vivienda, el conjunto de servicios e infraestructuras que delimitan oportunidades urbanas.

2 Si bien asumimos el género como construcción cultural de la diferencia sexual, que rebasa la dictomía mujer/varón, este artículo se focaliza en la experiencia de las mujeres y las relaciones que establecen con los varones. un juego permanente de complicidades y resistencias. Esta mirada implica aceptar la diversidad de posiciones en donde y desde las cuales el sujeto se construye, así como sus posibles tensiones y contradicciones. Caracterizamos este proceso como un tránsito de pacientes a dicientes (Rodríguez, 2009), que dialoga con las experiencias individuales de pacientes del Estado (Auyero, 2016) y su diferencia con la adquisición estratégica de "paciencia" por parte de las militantes del mismo sector social involucradas en contextos de organización colectiva (Procupez, 2015).

Nuestro análisis está centrado en el Movimiento de Ocupantes e Inquilinos (MOI), con énfasis en las experiencias de las cooperativas de hábitat y vivienda El Molino y La Fábrica. Este caso resulta apropiado para reflexionar acerca de las relaciones de género y su inscripción espacial, ya que se trata de una organización con una amplia base femenina, que avanza en la planificación y gestión de las propias condiciones de vida en la ciudad y con un objetivo explícito de aportar a un proceso más amplio de transformación social (Rodríguez, 2018, 2009, 2005). Distintas evaluaciones realizadas sobre sus asociadas, evidencian la mayor vulnerabilidad de las mujeres que están en situación de déficit habitacional, pero también dan cuenta de ciertos cambios a partir de su tránsito en la organización que involucran distintas dimensiones de la vida cotidiana (Enet, 2013). Esto se observa en los testimonios de las personas entrevistadas para esta investigación, quienes, además, ocuparon roles clave en la vida política de sus cooperativas. A su vez, las cooperativas elegidas para el análisis se inscriben en la ley 341 de autogestión del hábitat, que permite observar cómo interactúan la autogestión y la institucionalidad pública, y sus alcances en las relaciones de género.

La reflexión se organiza en torno al espacio de las relaciones sociales inscriptas en prácticas colectivas organizadas, dimensión con la que aludimos a una serie de instancias colectivas de toma de decisiones que habilitan la participación activa de las mujeres en la transformación de sus condiciones mate- 


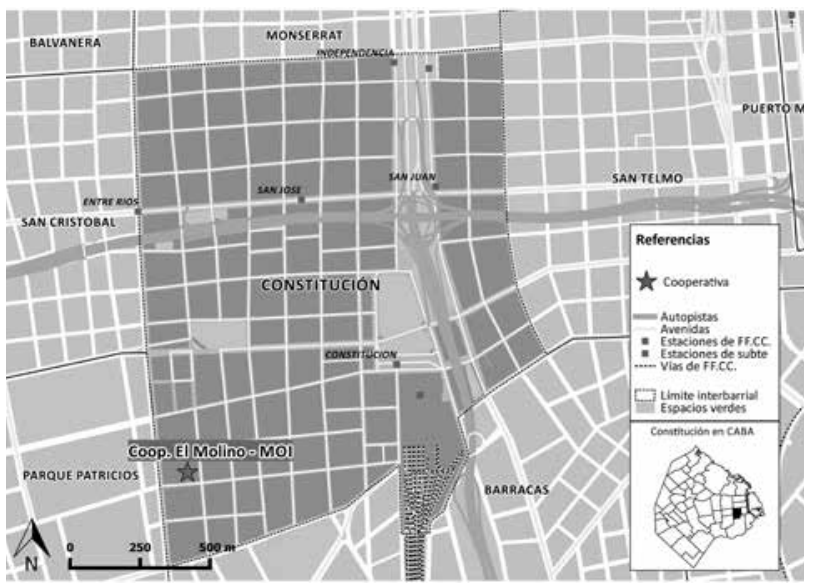

Figura 1. Ubicación de la Cooperativa El Molino. Fuente: elaboración propia.

riales de hábitat y de su vida cotidiana. Nuestro análisis se apoya en una perspectiva de participación observante (Guber, 2004) y en resultados de investigaciones específicas llevadas adelante desde 1991 sobre la experiencia del MOI (Rodríguez, 2018, 2009, 2005). Asimismo, se nutre de entrevistas etnográficas y de los datos de una encuesta realizada en marzo de 2018 el marco del proyecto "Alternative Models of Housing Development Programs in Buenos Aires, Argentina" compartido entre el Instituto de Investigaciones Gino Germani (Universidad de Buenos Aires) y John Hopkins University, y coordinado por las Doctoras María Carla Rodríguez y Valeria Preocupez.

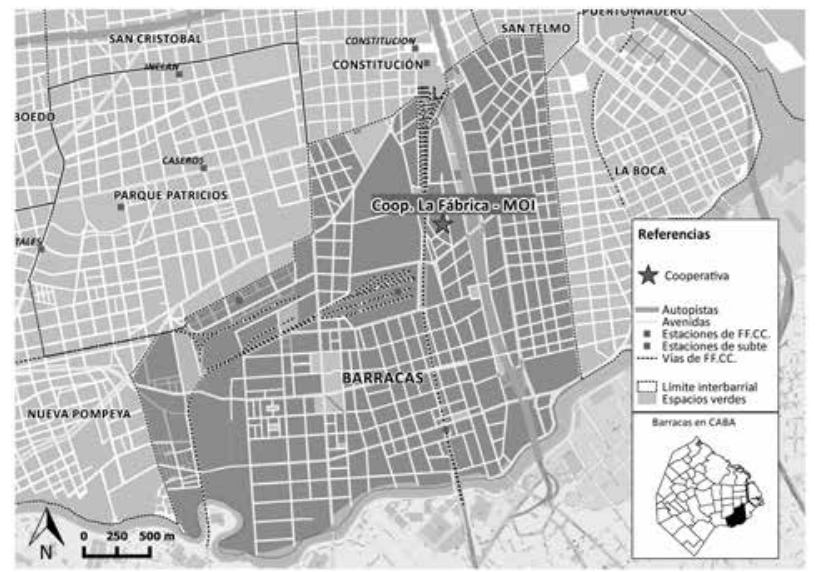

Figura 2. Cooperativa La Fábrica, ubicación dentro del barrio. Fuente: elaboración propia.
Este artículo se divide en tres apartados. El primero retoma algunas contribuciones realizadas desde los estudios urbanos, de género y sus cruces. El segundo avanza en un análisis a nivel mezzo sobre el diseño de la institucionalidad pública de producción autogestionaria del hábitat, que promueve procesos de mayor capacidad de decisión y autonomía de las mujeres respecto de las relaciones de género, en el contexto del empoderamiento de su posición social como clase. El tercero, realiza un abordaje a nivel micro de estas experiencias, poniendo de relieve el modo en que la producción autogestionaria del hábitat incide en las subjetividades y las contribuciones que realiza en ese contexto a procesos de despatriarcalización de las relaciones sociales. Por último, se reflexiona sobre lo trabajado.

\section{Capitalismo, espacio y género: algunas claves de lectura}

La relación entre ciudad y género ha venido cobrando importancia desde la década de 1970, a partir de los estudios pioneros de Burnett (1973) y Brueguel (1973). Aunque en América Latina esta línea es incipiente, inspiró diversas investigaciones, que se plasmaron en compilaciones y dossiers de revistas especializadas (Jirón y Zunino Singh, 2017; Falú, 2009; Molina, 2006; Massolo, 2004; Feijoó y Herzer, 1991, entre otros). Asimismo, en los últimos años, en pleno auge del movimiento de mujeres en Argentina, se observa un creciente interés en el tema y una ampliación del debate, que se expresa, por ejemplo, en la organización de eventos como los Seminarios-taller "Mujeres y Ciudad. [In]Justicias Territoriales" celebrados en 2017, 2018 y 2019 a instancias del Centro de Intercambio y Servicios para el Cono Sur Argentina (CISCSA).

Diferentes investigaciones pusieron de relieve los rasgos diferenciales que asume la experiencia cotidiana de los distintos géneros, y los diversos modos en que la organización del espacio contribuye a la profundización de las desigualdades socio-espaciales en la ciudad capitalista. Tal como 
señala Federici (2010 [2004]), el origen del orden patriarcal se encuentra estrechamente vinculado al desarrollo del capitalismo, en cuyo marco se produjeron una serie de transformaciones en la posición social de las mujeres. Específicamente, este proceso se sostuvo en una nueva división sexual del trabajo, en el que las mujeres fueron confinadas a las tareas reproductivas, dando lugar a una diferenciación con los hombres, que tuvo impacto en sus experiencias, vidas y relaciones sociales. De esta manera, la acumulación originaria implicó también una acumulación de divisiones, jerarquías y diferencias al interior de la clase trabajadora, en cuyo marco se intensifica la explotación. Aunque este proceso sufre transformaciones, los determinantes estructurales de este maridaje capitalismo-patriarcado continúan activos y son objeto de resistencias y disputas, en cuyo contexto se sitúa la reflexión sobre la autogestión como modo de organización de las relaciones sociales y su implicaciones políticas, económicas y culturales.

El espacio urbano modela y es modulado por procesos sociales, políticos y económicos, que reconfiguran y actualizan esas divisiones, diferencias y jerarquías entre los diferentes grupos sociales (Harvey, 2007; Topalov, 1979; Lefebvre, 1969). En esta línea, Ana Falú (2009), a partir de comprender el hábitat urbano como una construcción social, cultural, económica y política, con una historicidad específica y en la que intervienen diversos actores, pone de relieve la influencia mutua entre las relaciones sociales de género y la configuración espacial. En este marco, como evidencia Muxi Martínez (2015), los diversos aportes realizados por las mujeres al urbanismo y la producción de ciudad han sido menospreciados e invisibilizados. En paralelo, la planificación, su enseñanza y profesionalización han estado tradicionalmente en manos de los hombres, por lo que estuvo centrada en sus intereses, necesidades y prioridades (Ortiz Guitart, 2007).

Las ideologías patriarcales tienden a reforzar estos procesos a partir del uso de dicotomías geográficas como público-privado, productivo-reproductivo, movilidad-inmovilidad, que establecen representaciones espaciales de lo femenino y lo masculino, afectando el ordenamiento urbano y la estructura espacial (Soto Villagrán, 2016). En este sentido, se trata de clasificaciones que construyen sentidos sobre el lugar de hombres y mujeres, en donde ellas son relegadas a la esfera privada y familiar, tanto en el plano simbólico como en la materialidad concreta de la ciudad ${ }^{3}$. De esta manera, aun cuando la organización masculinizada del espacio no resulte determinante, los valores a ella asociados influyen de manera directa e indirecta en la vida cotidiana de las mujeres (Molina, 2006 en Soto Villagrán, 2016).

En este sentido, podemos decir que las formas de habitar la ciudad ${ }^{4}$ (Duhau y Giglia, 2008) de las mujeres asume características específicas, que condicionan la propia presencia en el espacio y las relaciones que allí se establecen. Pero, al mismo tiempo, no todas las mujeres viven la ciudad de la misma manera. La experiencia urbana (Duhau y Giglia, 2008) entre ellas, aun con sus puntos de contacto, varía en torno a otros atributos, como su ubicación socio-espacial, generando un diverso abanico de percepciones. En este contexto, las geografías cotidianas entre mujeres $-\mathrm{y}$ no solo entre hombres y mujeres - tienden a diferenciarse en torno a posiciones de clase, representaciones, estilos de vida, movilidad cotidiana y prácticas urbanas.

3 Un ejemplo de las expresiones que sumen estos procesos en la vida cotidiana de las mujeres es la ausencia de guarderías en los lugares de trabajo, y también la separación entre el lugar del trabajo y el hogar, es decir entre el ámbito de la producción y la reproducción. En este contexto, el ejercicio de la maternidad se encuentra limitado, o bien la mujer es excluida de la vida pública, con las consecuencias que esto tiene en términos de independencia y autonomía.

4 Aquí retomamos la definición elaborada por Duhau y Giglia (2008), quienes señalan que habitar la ciudad refiere al “(...) conjunto de prácticas y representaciones que hacen posible y articulan la presencia -más o menos estable, efímera, o móvil- de los sujetos en el espacio urbano y de allí su relación con otros sujetos" (p. 24). 
Si bien esas diferenciaciones se producen en torno a un abanico diverso de atributos, las políticas públicas han tendido a priorizar y centrar su atención en las mujeres pobres. Por un lado, los barrios vulnerables han sido priorizados en los programas de transferencias condicionadas a mujeres. Esas operatorias, sin embargo, generaron una serie de controversias, dado que conciben la pobreza y su "salida" como un fenómeno de índole individual, capaz de ser superado a través del esfuerzo personal de las mujeres a partir de los pequeños estímulos otorgados por los programas (Abramovich et. al., en Zibecchi, 2008). Por otro lado, los programas habitacionales, han tendido a acentuar las identidades de género y formas de organización tradicionales (Czytajlo, 2011), al tiempo que mantuvieron las divisiones tradicionales entre la vida pública y la privada en la proyección espacial de las viviendas, del espacio barrial y en sus relaciones con la ciudad (Rainero y Rodigou, 2003).

La bibliografía ha documentado también la participación de las mujeres en procesos de resistencia y movimientos reivindicativos y socioterritoriales de base urbana (Rodríguez, 2018; Gil y de Anso y Ramos, 2011; Massolo, 1995; Feijoó y Herzer, 1991). En esta línea, Feijoó y Herzer (1991) ponen de relieve la emergencia de manifestaciones diversas, que tienen en común el deseo por la transformación social del hábitat, encontrando en el territorio una oportunidad para el despliegue de formas de resistencia y lucha. Específicamente, se ha argumentado que las restricciones y carencias que impone el medio urbano alentó el surgimiento de este tipo de procesos, en particular entre las mujeres de sectores populares (Massolo, 1995). De este modo, las interpelaciones producidas a partir de los roles de género son detonadores de la proyección de las mujeres hacia la esfera pública, en donde se movilizan demandas y protestas que apuntan a los poderes y políticas urbanas. Las prácticas colectivas que en este marco se despliegan, constituyen una estrategia racional y creativa, en donde las mujeres aparecen como un actor social en los conflictos urbanos y la disputa por el derecho a la ciudad (Massolo, 1998). Las experiencias que este artículo retoma permiten observar este tipo de procesos así como lógicas alternativas de acceder, producir y apropiarse de la ciudad, en donde se tensionan las relaciones de género, en el contexto más amplio de la lucha por la transformación social y, con ella, de la ciudad.

\section{Efectos sobre las relaciones de género en la institucionalidad de la producción autogestionaria en clave de género}

La producción autogestionaria de hábitat se enmarca en la ciudad de Buenos Aires en la ley 341 del año 2001, que dio origen al Programa de Autogestión de la Vivienda (PAV). Esta normativa fue impulsada por una mesa multiactoral que funcionó durante el año 1999 y que estuvo conformada por diversas organizaciones de tierra y vivienda que venían desarrollando su acción en ocupaciones e inquilinatos $^{5}$. En este sentido, en la década de 1980 la "tolerancia" hacia las ocupaciones de edificios fue parte del clima de recuperación democrática, en donde no hubo a nivel local políticas habitacionales específicas para esta población (Relli, 2018; Rodríguez, 2005). En la década de 1990, se asistió a la progresiva instalación de la participación como dimensión significativa de la institucionalidad democrática, ante la sostenida crisis de representación que fue provocando el despliegue y profundización de las políticas neoliberales. En la ciudad de Buenos Aires, esto se expresó en la sanción de su Constitución en el año 1996, que promociona la autogestión en el artículo 31 "Hábitat", y en una diversidad de leyes entre las que se incluye la 341 .

De esta manera, la emergencia de la ley 341 está estrechamente vinculada a la capacidad auto-

5 Específicamente, por el Movimiento de Ocupantes e Inquilinos, el Movimiento Territorial de Liberación, la Organización Social y Política Los Pibes, la Mesa de Delegados de la Ex AU3 y sectores de la Iglesia vinculados al movimiento de sacerdotes por el tercer mundo. 
productora del hábitat de la población excluida por el mercado y las políticas públicas, que se dirigió no sólo a las periferias, sino también a la ocupación intersticial de la ciudad, buscando el acceso al conjunto de oportunidades que define la centralidad (vivienda, trabajo, educación, salud recreación, etc.). Estos procesos fueron protagonizados por una base social feminizada y empobrecida, que en primera instancia asume la organización reivindicativa como parte del desempeño de roles tradicionales del cuidado de la familia, los hijos y el hogar. En este sentido, en base a los planteamientos de Muxi Martínez (2015), podemos decir que en estos procesos se observan aportaciones a la producción de ciudad motivadas a partir del papel -asignado, obligado y menospreciado- de las mujeres en la reproducción del hogar.

El PAV, que es ejecutado por el Instituto de la Vivienda de la Ciudad, contempla el otorgamiento de créditos colectivos con tasas de interés subsidiadas (entre el $0 \%$ y el $4 \%$ ) y plazos de hasta 30 años de devolución, a organizaciones sociales para adquirir suelo, ejecutar obra nueva o reciclaje y contratar asistencia técnica interdisciplinaria (Zapata, 2017). El programa no contempla restricciones por nivel de ingresos familiar y reconoce como hogar al listado de personas convivientes declaradas por cada socio/a titular, incluyendo unifamiliares, por lo que habilita una diversidad de formatos que se desmarcan de estereotipos y preconceptos. Entre los años 2003 y 2007, se configuró un banco de 118 inmuebles adquiridos por cooperativas, que se localizan en barrios de renovación urbana (La Boca, San Telmo, Barracas, Parque Patricios, Mataderos). Hasta el año 2015 se construyeron aproximadamente 1200 viviendas en 40 conjuntos habitacionales (Zapata, 2017).

Las y los destinatarios de esta operatoria pueden optar por una determinada forma de organización colectiva, como cooperativas, asociaciones civiles o mutuales. Todas ellas involucran ciertos márgenes de libertad para elegir a las personas con quienes se asocian. Así, estos procesos, aunque complejos y diversos en sus resoluciones, conllevan la posibilidad de ejercer una decisión voluntaria de asociación. Estos hechos repercuten a futuro por tratarse de aquellos con quienes se vivirá en vecindad y se construirán lazos y redes de apoyo y cuidado - con vecinas, amigas y familiares- de gran valor para la resolución de la cotidianeidad de las mujeres. Esas redes voluntarias, a su vez, se constituyen en un importante apoyo en situaciones de violencia de género en el ámbito doméstico así como una contención en caso de que exista el deseo divorcio o separación. En este sentido, la recreación de la colectividad, cuando se traduce en prácticas concretas y cotidianas, habilita formas de vida comunitaria que aportan a la independencia y autonomía de las mujeres.

La asequibilidad como característica que asume el financiamiento en esta operatoria -bajas tasas de interés, plazos de devolución, proporción de ingresos familiares, etc.- puede ser afrontado por las mujeres y muestra, sobre este aspecto, una clara diferencia en relación con las tendencias generalizadas de endeudamiento de las mujeres de sectores populares (Gago, 2018). La feminización del problema habitacional está estrechamente vinculada a la inserción precaria y remuneraciones proporcionalmente más bajas de las mujeres, posicionándolas en una situación de mayor vulnerabilidad. La encuesta que realizamos en el marco del proyecto Alternative Models of Housing Development Programs in Buenos Aires, Argentina, evidencia que el $70 \%$ de los hogares que habitan en complejos construidos en el marco de la ley 341 tiene jefas de hogar, entre las cuales el $44 \%$ percibe ingresos equivalentes a un salario mínimo (contra el $28 \%$ de sus pares varones), que las sitúan en torno a la línea de indigencia. Por las características desmercantilizadas del proceso de producción autogestionaria del hábitat y la capacidad de gestión colectiva (Rodríguez, 2009), los costos fijos afrontados por estos hogares (cuota de devolución del crédito, cuota mantenimiento del conjunto y servicios de luz, agua y gas), no superan el $25 \%$ de estos ingresos, ni ponen en riesgo su permanencia 
en las viviendas que habitan. Esto pone de relieve la importancia que tienen los procesos colectivos desmercantilizados de producción del hábitat (Pírez, 2015) en la creación de condiciones que estrechan las desigualdades de género.

Asimismo, históricamente las mujeres han atravesado obstáculos particulares con relación a la seguridad de la tenencia, que atentan contra las posibilidades de una vida estable, autónoma, sin la amenaza constante del desalojo. La posibilidad que habilita el PAV respecto del acceso a créditos hipotecarios mediante un colectivo y sin presentar requisitos limitantes (por ejemplo, acepta la demostración de ingresos sólo por declaración jurada), reviste una gran importancia para la calidad de vida de las mujeres, principalmente aquellas que están solas a cargo de sus familias ${ }^{6}$. Si bien el problema de la titularidad femenina y la seguridad no tiene que ver estrictamente con impedimentos legales sino más bien ligados a limitaciones de las propias políticas públicas de acceso a la vivienda, a prácticas culturales y a las condiciones en que se insertan en el mercado laboral, lo cierto es que las mujeres se ven afectadas de forma desproporcionada -con relación a los varones- por los desalojos forzosos y las relocalizaciones. En este mismo sentido, la práctica de propiedad colectiva inspirada en el modelo cooperativo uruguayo que impulsan varias organizaciones, es un aspecto significativo en la construcción de seguridad de tenencia.

Por último, otra particularidad de la Ley 341, es que son los propios colectivos quienes eligen su localización en la ciudad, a partir de la compra de un terreno con el crédito otorgado en el marco del PAV. La mayor parte de las organizaciones

\footnotetext{
6 Cabe señalar que al interior de las organizaciones se construyen lazos de solidaridad que rompen con las lógicas individualizantes -e individualizadoras- del capitalismo. Por ejemplo, si una familia, por motivos laborales o personales, no logra estar al día con la cuota para la devolución del crédito hipotecario, la organización responde por ella, asegurando la permanencia en la vivienda. Para eso, resulta frecuente el desarrollo de mecanismos de ahorro colectivo que recrean criterios de reciprocidad extramercantiles.
}

incluidas en la operatoria eligieron establecerse en barrios de localización central. Esto remite a formas de apropiación y uso del espacio urbano con efectos concretos en los modos de habitar (Duhau y Giglia, 2008) de las mujeres, tanto por su incidencia en el acceso a las oportunidades urbanas como por las relaciones que desde allí se establecen con el resto de la ciudad. En este sentido, el lugar en donde se reside funciona como centro de un área de movilidad (Di Virgilio, 2007), condicionando los desplazamientos cotidianos que permiten el acceso a personas, objetos y lugares (Jirón, Lange y Bertrand, 2010). La localización central en la ciudad y el mejor acceso al sistema de transporte, favorece el desarrollo simultáneo de tareas de producción y reproducción, que tienden a caracterizar la vida de las mujeres de los sectores populares. Si bien esta particularidad no implica un estrechamiento de las desigualdades de género, favorece una ruptura con la esfera de "lo privado" y abre un abanico de posibilidades que, en muchas trayectorias personales, se traducen en la finalización de estudios de nivel primario y secundario, el inicio de carreras universitarias, el impulso de emprendimientos laborales propios o de mayor calificación laboral y el impulso a participar en otras actividades organizativas y sindicales, entre otros.

\section{La producción autogestionaria del hábitat y los procesos de despatriarcalización en cooperativas del MOI}

\section{Características de las cooperativas y los proyectos}

Las cooperativas El Molino y La Fábrica ${ }^{7}$ se constituyeron a través de un espacio específico de convocatoria, capacitación y organización cooperativista estructurado por el MOI, que funcionó a

7 Las características de estos proyectos se describen con mayor detalle en Rodríguez (2009). 


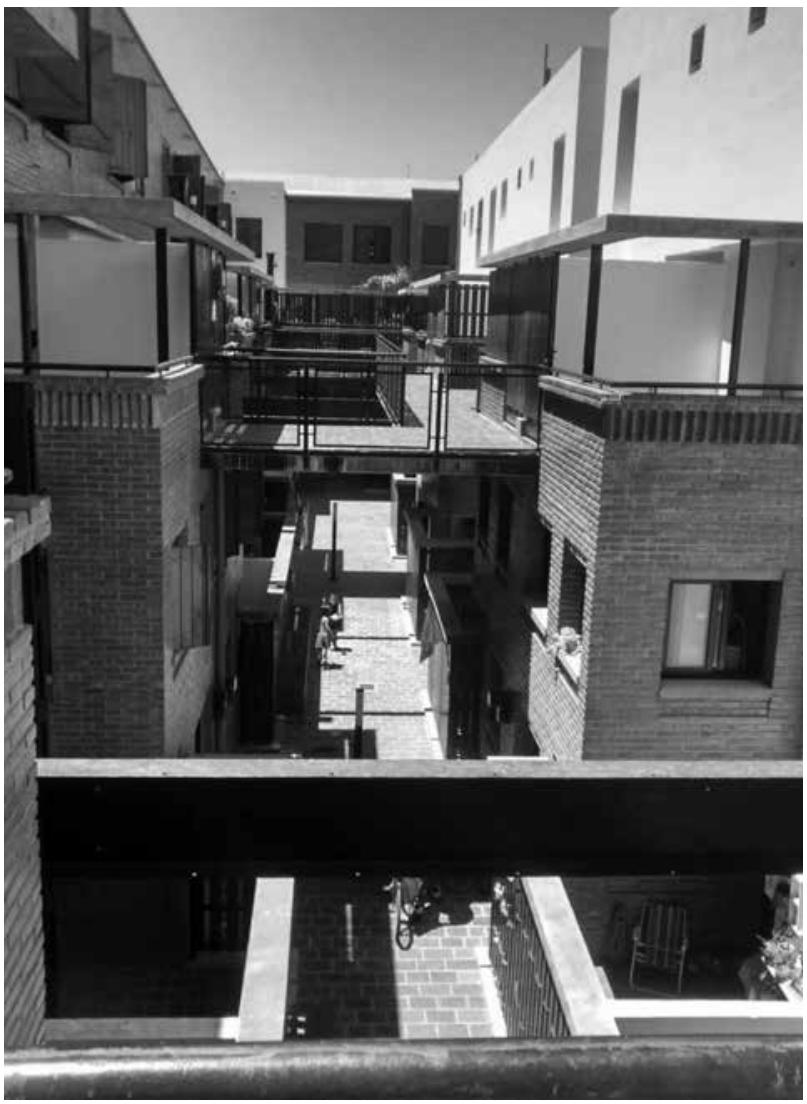

Figura 3. Cooperativa La Fábrica. Fuente: elaboración propia.

partir de 1999 en el barrio de San Telmo, denominado "guardias de autogestión".

La Fábrica, data del año 2000. El predio en donde construyó su conjunto habitacional, inaugurado en diciembre de 2017, fue una de las primeras compras concretadas por la Ley 341, el 10 de diciembre de 2001. Por U\$S 750.000 dólares adquirió un inmueble de tipo fabril, de aproximadamente 2200 $\mathrm{m}^{2}$, que aloja 50 familias con trayectorias habitacionales heterogéneas ${ }^{8}$. El predio se localiza en el

8 Específicamente, trabajadores formales e informales que habitaban en alquileres formales, informales, ocupantes de edificios e integrantes de programas de vivienda transitoria del MOI. Mas allá de la rotación producida en 17 años (solo quedan 5 familias originales del proyecto), el perfil socioeconómico y habitacional de la cooperativa se mantuvo. En El Molino, por el contrario, se modificó, tendiendo a una mayor heterogeneidad similar a la de La Fábrica.

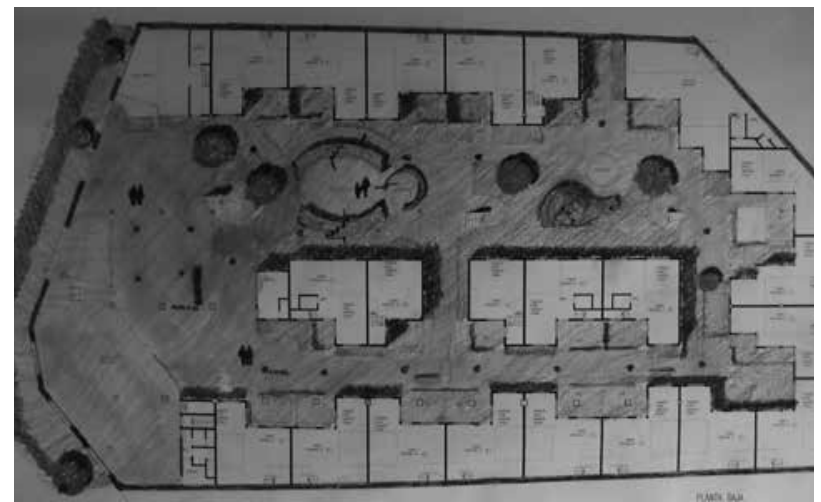

Figura 4. Planta Cooperativa La Fábrica. Fuente: elaboración propia.

barrio de Barracas, en un sector implicado en un proceso de renovación urbana, frente al complejo de alta gama "Barracas Central" y adyacente al punto turístico-cultural "Pasaje Lanín”. El proyecto de La Fábrica involucra 50 viviendas en tipología dúplex, dos salones de usos múltiples, un local comercial y una planta interior de expansión. En julio de 2001 la cooperativa modificó su estatuto adoptando el sistema de usuarios (propiedad colectiva) y el sistema de ejecución autogestionario y por ayuda mutua.

La cooperativa El Molino se gestó durante una situación de crisis habitacional producida a mediados de 2001 en hoteles subsidiados por el GCBA para familias en emergencia habitacional.

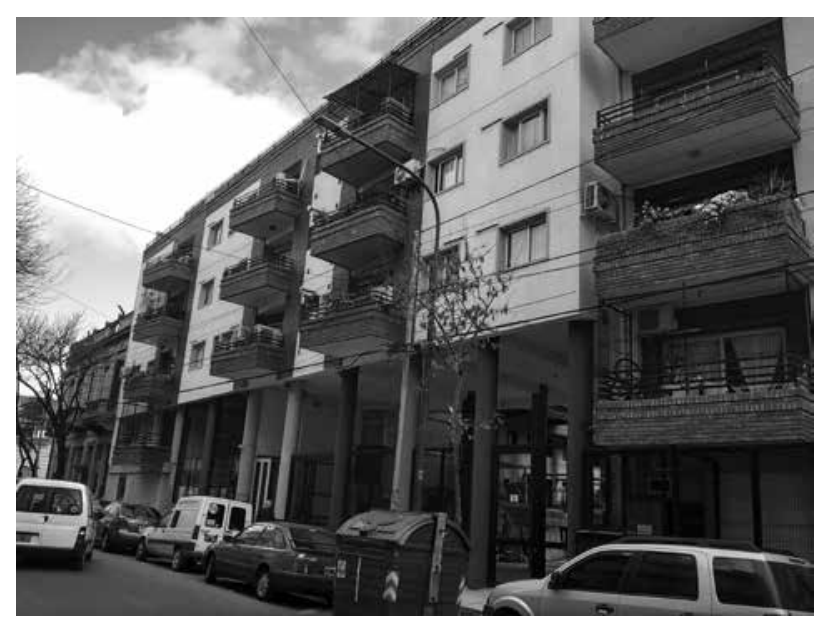

Figura 5. Cooperativa El Molino. Fuente: elaboración propia. 
La cesación de pagos a los propietarios por parte del gobierno local, produjo un estado de alerta, movilización y la organización de "mesas de hotelados". Dos de estos grupos tomaron contacto con el MOI y durante el primer semestre de 2002 constituyeron un proyecto unificado. El 5 de julio de 2002, la cooperativa adquirió por U\$D 850.000 dólares un predio de $3500 \mathrm{~m}^{2}$, con capacidad para 100 familias y equipamiento comunitario. El inmueble se localiza en el barrio de Constitución, en una zona de uso residencial unifamiliar, con presencia de hoteles pensión y algunos edificios en altura. El Molino, concebido en 4 etapas, de las cuales se han concluido 3 , conjuga obras de reciclaje (recuperación de un silo y galpones de tradición funcional inglesa tipo loft) y la ejecución de edificios de obra nueva para 100 unidades de vivienda. Asimismo, incluye el reciclaje de un edificio central de 4 plantas, en donde se emplazan un salón de usos múltiples y el jardín de infantes "Construimos Jugando".

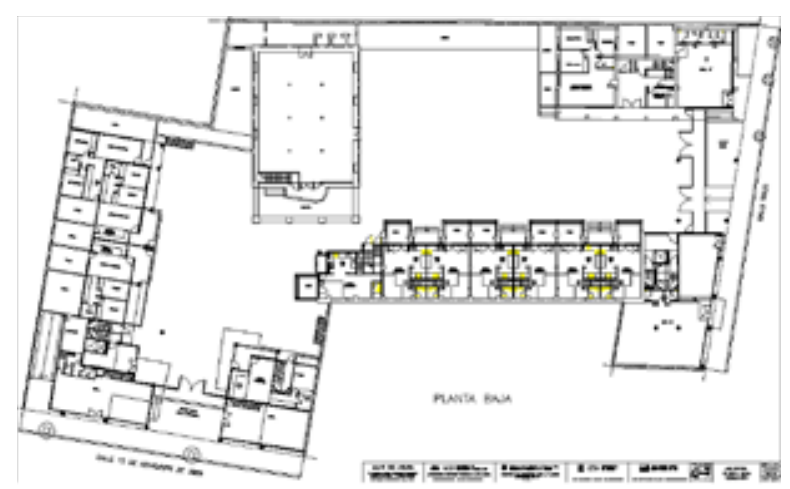

Figura 6. Planta Cooperativa El Molino. Fuente: elaboración propia.

\section{Efectos de la participación decisoria y la institucionalidad cooperativa autogestionaria}

Cristina llegó al MOI en el año 2001. Vivía con sus hijos en un hotel del Gobierno de la Ciudad (GCBA) desde que se había separado de su marido. Ese año, en el contexto de la crisis habitacional en los hoteles subsididados, conformó con otro grupo de personas la cooperativa El Molino. Pato, de cooperativa La Fábrica, se integró al MOI en el año 2005. En ese entonces, vivía con su pareja en una habitación de $12 \mathrm{~m}^{2}$ de un conventillo tomado, en donde había comprado "la llave" a la persona que administraba el uso del lugar. Antes de su ingreso al MOI, "no creía en estos procesos" ni se "involucraba en estas cosas". Sin embargo, "abrió mucho la cabeza en la organización", cuyos arreglos institucionales configuran un entramado de instancias colectivas de toma de decisiones, que posibilitan un proceso de aprendizaje e involucran colectiva, activa y reflexivamente a las mujeres en la obra de sus condiciones materiales de vida y las sitúa en el umbral de acceso a la vida política. Hemos caracterizado este proceso como el tránsito de pacientes a discentes ${ }^{9}$ (Rodríguez, 2009).

Adoptamos dicho neologismo de Paulo Freire, para dar cuenta de una transición que ocurre en determinados contextos colectivos de circulación de la palabra, con una cualidad dialógica, es decir, de posibilidad de escucha e intercambio que "cambia los pensamientos". En este proceso, la condición individual de pacientes del Estado señalada por Javier Auyero (2012) se transforma en la adquisición de una paciencia estratégica, tal como la ha caracterizado Valeria Procupez (2015).

La experiencia de la espera, que transforma a las personas en pacientes, es una de las modalidades de ejercicio de dominación por parte del Estado, que enfatiza los efectos del ejercicio del poder sobre la percepción del tiempo (Auyero, 2015). Las instancias de urgencia desesperada y de postergación intolerable de las personas esperando ser relocalizadas tras el incendio de una villa o de un entorno barrial altamente contaminado o a la espera de subsidios en las oficinas de acción social, las privan de capacidades de acción y, por ende, de su condición de ciudadanía. Procupez (2015) señala que esta percepción de la espera,

\footnotetext{
9 Adoptando el neologismo de Paulo Freire que alude al proceso de aprendizaje basado en la circulación dialógica de la palabra entre los participantes, que permite "pensar acertadamente" es decir, con capacidad de reflexión crítica y por ende, modificación, sobre sus propias prácticas.
} 
también es moldeada por quienes esperan, los sujetos/as y sus capacidades de resignificación. En su reflexión, sobre las luchas de activistas mujeres enmarcadas en contextos de organización colectiva $^{10}$, ella identifica la emergencia de un sentido de agencia diferente y complejo que resulta de la intersección de vectores temporales heterogéneos: la urgencia de las necesidades, las demoras e incongruencias administrativas, las soluciones provisorias, las expectativas esperanzadas. Las militantes adquieren "paciencia" cuando avizoran un fin colectivo que, lejos de la pasividad y el conformismo, involucra la aceptación de trabajar en común por un objetivo de largo plazo. ¿Cómo se constituyen esas capacidades? Identificamos algunas aristas de ese proceso, en nuestra propia praxis y trabajo de campo, a saber:

\section{i) La recreación de una experiencia cotidiana} de la dimensión colectiva: el entramado

Asamblea-Comisiones-Consejo de Administración

Ambas cooperativas, a instancias del MOI, desarrollaron una estructura organizacional en tres niveles: un espacio asambleario, que constituye el corazón de la dinámica cooperativa; el consejo de administración - que es su ámbito de representación institucional -; y una estructura intermediaria de comisiones -participación, aportes y ayuda mutua- destinadas a operativizar las tareas de la cooperativa de acuerdo a cada etapa. La organización interna conllevó a la formulación de instrumentos normativos específicos para regular la vida cooperativa (reglamento interno, de ayuda mutua y adjudicación) que fueron elaborados por las y los cooperativistas junto con la asesoría de los profesionales del equipo interdisciplinario del MOI. Este entramado de instancias, funciones

10 Valeria Procupez trabajó con militantes del MOI involucradas en Cooperativa El Molino y La Fábrica, en una experiencia de Programa de Vivienda Transitoria, durante la primera década del siglo XXI. Se trata de otro dispositivo organizativo de fundamental importancia en la socialización cooperativa, que aquí no desplegamos por razones de extensión. y recreación de las normas, que semanalmente involucra muchas horas de trabajo y debate vividas en común, configura la base de la convivencia y el mantenimiento edilicio durante la etapa del habitar y, en su sentido menos tangible pero de profundos efectos, habilita el proceso de re recreación de la significación cultural del espacio vivido y el proceso de transformación subjetiva.

La especialización de tareas y delimitación de roles derivada de esta estructura organizacional requirió de un aprendizaje progresivo e interactivo, que presentó dificultades y conflictos de diverso tipo, cuyo ajuste y superación constituye la capacidad autogestionaria de cada grupo. En dos años, las cooperativas habían generado una dinámica propia, y al mismo tiempo, interdependiente, con la vida del movimiento. La participación en estas estructuras fue mayoritariamente femenina, en correspondencia con la composición de la base societaria. En este sentido, Pato señala que "Por lo general, en el trabajo de la cooperativa, lo que es la asamblea, el consejo, la ayuda mutua...la vida propia de la cooperativa, la mayoría son mujeres". Esta presencia y papel de las mujeres en los espacios decisorios produce, en palabras de Pato, "chasquerridos, chicaneadas, chistes machistas", pero que habilitan oportunidades para, dentro de esos espacios, avanzar en procesos de deconstrucción de las relaciones patriarcales.

La participación de las mujeres en espacios de decisión dio lugar a temas y propuestas que inciden en la vida cotidiana de la cooperativa y proyectan una espacialidad alternativa. Concretamente, Pato relata que "la mayoría de las que bancábamos la ayuda mutua éramos mujeres. Obviamente muchas no tenían donde dejar a sus niños (...)" y en ese marco surgió el espacio de "recreación" en un sector de la obra, "Entonces nosotras veníamos a hacer ayuda mutua, y las compañeras que eran mamás, venían con sus criitos, y nosotros nos turnábamos para cuidar y que ellas pudieran hacer la ayuda mutua". En el caso de El Molino, esa participación dio lugar al Jardín "Construimos Jugando", desarrollado a partir del año 2005 por la iniciativa 
de mujeres del movimiento que devinieron en educadoras populares. Este proyecto trascendió el proceso de obra y en la actualidad constituye una escuela pública barrial, sostenida y enmarcada en la oferta estatal, que ofrece una propuesta pedagógica distintiva (pedagogía de la ternura y desarrollo motor autónomo). El Jardín, además, es una fuente de trabajo dignamente remunerado y un ámbito de aprendizaje para mujeres y varones de la cooperativa. ${ }^{11}$

\section{ii) El ejercicio cotidiano de la participación decisoria (niveles y tensiones en el propio proyecto y en el movimiento)}

A lo largo de los años, las cooperativas experimentaron ciclos de alzas y bajas de la participación y distintas crisis grupales. En esos procesos fueron adquiriendo capacidad de autorregulación, generaron dinámicas de cooperación entre cooperativas (compras conjuntas de materiales, préstamos internos, gestiones conjuntas) y por momentos, de competencia. Aunque con matices, una marcadamente asamblearia (La Fábrica) y la otra notoriamente consejista (El Molino), ninguna cayó en formatos de conducción unipersonales, corrientes en otros formatos de experiencias, y las estructuras intermediarias se estabilizaron como ámbitos de organización práctica de la vida cooperativa.

Pato y Cristina identifican diferencias en los estilos de liderazgo de varones y mujeres, que se reflejan en las prácticas al interior de la organización y que producen tensiones al interior de los proyectos.

11 En este Jardín Maternal, las educadoras reflexionaban que al recibir capacitación sobre la ESI se dieron cuenta que ellas ya desarrollaban cotidianamente muchos aspectos, desde el cuidado y respecto del cuerpo de les niñez (por ejemplo a los bebés se les pide permiso y se les explica que se los va a cambiar), la no identificación de roles de género en los juegos propuestos (posibilitando que se disfracen, maquillen o jueguen con aquello que elijan sin distinguir género) y proponiendo escenarios de juego creativos y no sesgados como "los viajes espaciales", "la exploración de la selva" "el "fondo del mar" "el laboratorio científico".
En este sentido, Pato relata que algunos de sus compañeros, que tienen un rol importante en las instancias administrativas de la cooperativa, "no pasan información o no transmiten a los compañeros como son las cosas". En su opinión esto es "no tener en cuenta al compañero como vecino, como luchador que vamos codo a codo". Ella, "desde su rol de mujer" y en su papel de presidenta de la cooperativa La Fábrica, trata de "no confrontar, de ver cómo se puede unir al grupo, cómo puede vivir el espíritu cooperativista acá adentro".

La salida de El Molino del MOI en el año 2015, enmarcada en el triunfo electoral de una dirección "independentista" - que cuestionaba aspectos del modelo productivo y la forma de propiedad colectiva impulsadas por el movimiento-dio paso hacia un modelo consejista, que trajo aparejado un estilo de conducción más patriarcal y viviendista. En este marco, Cristina señala que "cuando nosotras, las mujeres del MOI, proponemos cosas a la cooperativa, ellos se niegan. Se niegan los varones... a pesar de que serían las soluciones". Estos varones, a su vez, se sostienen en la anuencia de un conjunto de mujeres migrantes de incorporación más reciente a la cooperativa, que asumen una posición delegativa y más tradicional de aceptación de dicho liderazgo. La presencia del grupo de mujeres ligadas al MOI y del Jardín tiende a tensionar ese modelo, a partir de producir un escenario de conflictividad que visibiliza las diferencias en los criterios, estilos de liderazgo y procesos de decisión, y que deja abierta la posibilidad para avanzar en la construcción de otros vínculos al interior de la cooperativa, que implica un aprendizaje de la convivencia en diversidad, sin anular las minorías o negar al otro. Un aspecto no menor, es que las mujeres que actualmente protagonizan esta disputa, jugaron un papel activo en su cooperativa $y$ en el movimiento, en cuyo marco atravesaron un proceso de transformación de prácticas que en la actualidad las pone en un lugar más autónomo y combativo, apoyado en una creciente capacidad de negociación. De este modo, unas y otros, son parte de una convivencia democrática, que asume al conflicto como parte de la misma. 


\section{iii) La práctica de ayuda mutua durante la ejecución de los proyectos}

La incorporación de ayuda mutua en el proceso de ejecución de las obras, implica un aporte concreto de mano de obra de los destinatarios y destinatarias que favorece la cohesión grupal, abaratamiento de costos, campo de calificaciones. Si nos detenemos en la experiencia del MOI, se puede observar cómo las mujeres de distintas edades trabajan en la obra junto a los varones, desafiando la ideología patriarcal que naturaliza ciertos roles o "lugares de la mujer" y habilitando un espacio de aprendizaje y de solidaridad donde, sobre todo los varones, comienzan, poco a poco, a ver más allá de los estereotipos femeninos.

En esta línea, Pato señala que las mujeres en la ayuda mutua "trabajan a la par que un hombre" y realizan todas las tareas de la obra. Han "hecho pozos, paleado, tirado columnas”. Para la mayoría de ellas, fue su primer acercamiento al ámbito de la construcción. A partir de esta experiencia, Pato se dio cuenta que "quisera trabajar en la cooperativa de trabajo" del movimiento, "porque [a ella le] gusta mucho la obra. La comunicación, el estar, el tomar un mate, poner un ladrillito, desmontar el techo".

No obstante, son muy pocas las mujeres que han tomado la decisión de trabajar en la cooperativa de obra, mostrando la persistencia y profundidad de dispositivos que requieren mayor elaboración y sustento en la estrategia de desmonte de las percepciones e identificaciones de los roles tradicionales de género.

\section{Construyendo sin ladrillos: subjetividades que problematizan los roles tradicionales de género}

Como señala Judith Butler (2006), el género constituye el mecanismo a través del cual se producen y se naturalizan las nociones de lo masculino y lo femenino, pero el género también puede constituir el aparato a través del cual dichos términos se deconstruyen y se desnaturalizan. El mismo aparato que trata de instaurar la norma, puede funcionar para socavar esa misma instauración y, que ésta sea, por así decirlo, incompleta por definición.

En la experiencia del MOI, la organización colectiva es afrontada por muchas mujeres como forma de asumir roles tradicionales de cuidado y protección familiar. Sin embargo, promover la autogestión no solo implica el acceso a un techo y a un entorno urbano, sino que también habilita -de manera lenta, pero sostenida- marcados procesos de empoderamiento que se observan, en los roles que desempeñan tanto varones como mujeres. Estas transformaciones van de la mano de los nuevos espacios que las mujeres pasan a ocupar cuando las políticas públicas habilitan una participación activa. Tanto Cristina como Pato, fueron presidentas de sus respectivas cooperativas en momentos difíciles. Cristina, al inicio, cuando todo era proyecto. Pato al momento de mudarse a las viviendas definitivas, cuando la organización -cumplidos algunos objetivos- corre peligro de debilitarse.

En este sentido, los espacios de participación de las mujeres dentro de organizaciones como el Movimiento de Ocupantes e Inquilinos son múltiples, y se observa que progresivamente pasan a ocupar cargos directivos y de responsabilidad política, aun cuando en la mayoría de los casos, nunca habían tenido experiencia política o comunitaria. Al mismo tiempo, han desarrollado un área de género que habilita marcos de experiencias compartidas y sostén recíproco y que se mantiene persistente, junto con la participación en los Encuentros Nacionales de Mujeres. Concretamente, el involucramiento en las prácticas autogestionarias de producción del hábitat, las impulsa a salir a la escena pública, aspecto que incide positivamente en su autoestima, se plasma en su vida diaria y las reposiciona de cara al futuro. Esto era señalado por Pato, que nos contaba, "Yo aprendí a pensar de otra manera. Ahora tengo sueños. Sé que se puede seguir construyendo [...] Yo fui aprendiendo un montón de cosas y también aprendí a decir que no y a pensar un poquito más en mí, que no es un tema 
menor". De esta manera, a partir del análisis de la experiencia del MOI, pueden observarse indicios de un viraje desde una actitud pasiva y vinculada al rol de madre, esposa y ama de casa, hacia un nuevo perfil activo que demanda, lucha por sus derechos, gestiona recursos, protesta, negocia y se reconoce capaz de ejercer influencia sobre otros. Es un tránsito no lineal, atravesado por una sucesión de conflictos internos y de interacción, marchas y contramarchas, cansancios, desgaste y rupturas. Sin embargo, las mujeres crecen, se vuelven más seguras y dan cuenta de vidas que se han tornado más habitables.

Dentro del proyecto colectivo autogestionario del movimiento, los procesos de integración social se generan a partir de la idea de singularidad del sujeto, opuesta a una concepción normalizadora portadora de grandes categorías unificadoras. El desarrollo de modos de subjetivación singulares tiene que ver con la confección de otras formas de sensibilidad, de relación con el otro, de creatividad, de producción; con una singularización existencial que coincida con un deseo, con un gusto por vivir, con una voluntad, todo ello dirigido a realizar cambios y/o aperturas en el sistema de subjetividad dominante (Guattari y Rolnik, 2005). Así, Pato, relata que "yo aprendí muchísimo políticamente, [antes] vivía adentro de una burbuja [...] [aprendí] a trabajar en un colectivo, a mirar a los demás, a no ser tan incrédula y aprendí que uno puede [...], me sensibilicé mucho. Señala que ella "era muy introvertida, no hablaba mucho, [le] costaba mucho hablar en público, sentía que no tenía palabras [...] y ahora [se] expresa de mejor manera, más abierta, sin miedo, diciendo lo que [piensa]". Cristina, que "jamás había participado de una organización, jamás había ido una marcha, jamás nada”, aprendió a decir "no" a su marido y sus hijas e hijos. Para ella, a partir del tránsito por la organización, "la vida de uno hace como un click y cambia. Se transforma”.

Pato también mencionaba que ese proceso de transformación se reflejó en sus actividades diarias, "en [su] trabajo, en [su] comunicación con las otras personas... hasta en ir a un almacén y pelear un precio". Acompañando estos procesos, las prácticas colectivas autogestionarias implican transitar y construir nuevos espacios de sociabilidad en los cuales se co-producen nuevos significados e historias: la continuación de los estudios, la liberación del tiempo de cuidado destinado a los hijos pequeños -porque hay dispositivos comunitarios en los cuales apoyarse-, el plantearse asumir nuevos tipos de trabajos, en alguno casos la redistribución de las tareas domésticas, el transitar nuevos espacios de sociabilidad ${ }^{12}$. Así, por ejemplo, Cristina se recibió de bachiller rondando los 50 años y en su tránsito, sostiene, "abrí un poco más mi cabeza". Para Pato, "entrar a la organización, haber transcurrido, transitado por el bachillerato, haber estudiado después de tantos años, a mí me sirvió mucho [a nivel personal] y también me sirvió mucho para el trabajo. A nivel de 'respetame los derechos"'.

\section{Reflexiones Finales}

Hemos puesto de manifiesto las múltiples aristas a través de las cuales las prácticas de producción autogestionaria del hábitat, con centralidad en el fortalecimiento de una dimensión colectiva y organizada que estructura espacios significativos de la vida cotidiana, dan lugar a procesos de resignificación cultural que posibilitan un distanciamiento de roles y prácticas naturalizadas, entre ellas las de género.

En el plano más general del diseño, contenidos y efectos de las políticas, el proceso de la Ley 341, con su particularidad de institucionalidad modelada a partir de la participación significativa (y no meramente formal), tuvo claros efectos sobre las

12 Esto se puede observar en los contenidos curriculares de los bachilleratos populares; los cuestionamientos explícitos de lugares tradicionales de feminidad/ masculinidad; la naturalización de diversas orientaciones de género en los ámbitos cotidianos; las relaciones fraternas con organizaciones que problematizan estas temáticas (estableciendo áreas de género, relaciones con colectivos feministas, varones antipatriarcales, etc.). 
relaciones de género. En primer lugar, potenció la capacidad autoproductora y creadora del hábitat de las participantes, abrió las puertas a la experiencia del ejercicio de la decisión voluntaria de asociación con sus repercusiones futuras sobre la vida cotidiana, su conflictividad, pero también su desarrollo subjetivo autónomo. En segundo lugar, estableció condiciones asequibles, -bajas tasas de interés, plazos de devolución, proporción de ingresos familiares, etc- que pueden ser afrontadas en clara diferencia con las tendencias generalizadas de endeudamiento de las mujeres de sectores populares (Gago, 2018). Por último, permitió establecerse en barrios de localización central, con clara incidencia en el acceso a las oportunidades urbanas y las relaciones que desde allí se establecen con el resto de la ciudad.

La reorganización de la vida cotidiana así experimentada, conjuga coordenadas que involucran la tríada ámbito-actividad-usuario (Winograd, 1988) en donde se forja la nueva subjetividad a través del desarrollo de mayores competencias reflexivas junto con la movilización de afectividades. En esa experiencia integral, se entrama la tarea de resignificación cultural que incluye tendencias despatriarcalizadoras de las relaciones sociales. Se procesa la experiencia biográfica, se abren nuevas posibilidades de percepción y se enuncian nuevas narrativas en un proceso que involucra, como señalaba Lefevbre (1969) "contradicción, deseo y razón”.

Estas tendencias trasnformadoras, se despliegan junto con la incorporación de nuevas prácticas que resignifican el espacio vivido. Junto con la producción de su nueva materialidad habitacional, se adquieren competencias para actuar y disputar el derecho a la palabra -y el saber de la escucha- en la escena colectiva/comunitaria y, desde ese ámbito mediador intermediario, se interpela lo privado/ familiar, la esfera pública y las identificaciones subjetivas de género.

De este modo, los nuevos arreglos institucionales que encausan el proceso de producción autogestionaria del hábitat -en el Estado así como en los planos organizativos internos-, conllevan la recreación de "lo común", ámbito donde despatriarcalización y desmercantilización se enlazan e implican el despliegue de una politicidad de la cotidianeidad a través de la recreación de una narrativa biográfica, entramada en una historicidad recuperada, o en otras palabras, de la recreación de un contexto colectivo que potencia individualidades.

\section{Referencias bibliográficas}

Auyero, J. (2016). Pacientes del Estado. Buenos Aires: Eudeba.

Bonder, G. (1999). Género y subjetividad: avatares de una relación no evidente. En: Montecino, S. y Obach King, A. (comps.). Género y Epistemología. Santiago de Chile: Universidad de Chile - Lom ediciones.

Butler, J (2006). El reglamento del género. En: Deshacer el género. Barcelona: Paidós.

Bruegel, I. (1973). Cities, women and social class: a comment. Antipode, 5 [3], pp. 62-63.

Burnett, P. (1973). Social change, the status of women and models of city form and development. Antipode, 5 [3], pp. 57-61.

Czytajlo, N. P. (2011). Espacio, género y pobreza: discursos, prácticas y construcción de subjetividades en torno al proceso de implementación de políticas habitacionales. Barrios del sector noroeste de la periferia urbana de San Miguel de Tucumán (2004-2008). Temas de Mujeres, 7[7], pp. 253-274.

Di Virgilio, M. M. (2007). Trayectorias residenciales y estrategias habitacionales de sectores medios y populares en Buenos Aires. Tesis de doctorado no publicada. Doctorado en Ciencias Sociales, Facultad de Ciencias Sociales, Universidad de Buenos Aires.

Duhau, E. y Giglia, A. (2008). Las reglas del desorden. Habitar la metrópoli. México: Universidad Autónoma Metropolitana.

Enet, M. (2013). Informe Final. Federación de Cooperativas Autogestionarias MOI. Evaluación Externa. Buenos Aires: Mimeo. 
Falú, A. (ed.). (2009). Mujeres en la ciudad. De violencias y derechos. Santiago de Chile: Red Mujer y Hábitat de América Latina - Ediciones Sur.

Federici, S. (2004, ed. 2010). Calibán y la bruja. Mujeres, cuerpo y acumulación originaria. Madrid: Traficantes de Sueños.

Feijoó, M. y Herzer, H. (1991). Las mujeres y la vida en las ciudades. Buenos Aires: CEAL.

Gago, V. y Cavallero, L. (2018). Una lectura feminista de la deuda. Buenos Aires: Fundación Rosa Luxemburgo.

Gil de Anso, M. L. y Ramos, J. (2011). La casa, el barrio, la ciudad: algunas consideraciones de género a partir de la experiencia del Movimiento de Ocupantes e Inquilinos. En: Di Virgilio, M., Herzer, H., Merlinsku, G. y Rodríguez, M. C. (comps.), La cuestión urbana interrogada. Transformaciones urbanas, ambientales y politicas públicas en Argentina. Buenos Aires: Café de las ciudades.

Guattari, F. y Rolnik, S. (2005). Micropolitica. Cartografías del deseo. Madrid: Traficantes de sueños.

Guber, R. (2004). El salvaje metropolitano. Reconstrucción del conocimiento social en el trabajo de campo. Buenos Aires: Paidós.

Harvey, D. (2007). Espacios del capital. Hacia una geografía crítica. Madrid: Akal.

Jirón, P. y Zunino Singh, D. (2017). Dossier. Movilidad urbana y género: experiencias latinoamericanas. Transporte y Territorio (16), pp. 1-8.

Jirón, P., Lange, C. y Bertrand, M. (2010). Exclusión y desigualdad especial: retrato desde la movilidad cotidiana. Revista INVI, 25(68), pp. 15-57.

Lefebvre, H. (1969). El derecho a la ciudad. Madrid: Península.

Massolo, A. (comp.). (2004). Una mirada de género a la ciudad de México. México: UAM-Azcapotzalco / Red Nacional de Investigación Urbana.

Massolo, A. (1995). Testimonio autobiográfico. Un camino de conocimiento de las mujeres y los movimientos urbanos en México. La ventana, (1), pp. 62-84.

Molina, I. (2006). Rompiendo barreras: género y espacio en el campo y en la ciudad. Santiago de Chile: El tercer actor.

Muxi Martínez, Z. (2015). Mujeres haciendo ciudades: aprendiendo del pasado. Kultur, 2(3), pp. 111-124.

Ortiz Guitart, A. (2007). Hacia una ciudad no sexista. Algunas reflexiones a partir de la geografía humana feminista para la planificación del espacio urbano. Territorios, (16-17), pp. 11-28.

Pírez, P. (2015). La urbanización en América Latina: Las heterogeneidades en su producción y resultados. Ponencia presentada en I Congreso Latinoamericano de Teoría Social. Buenos Aires. Argentina.

Procupez, V. (2015). The need for patience. The politics of housing emergency in Buenos Aires. CurrentAnthropology56(11),pp.855-865.Disponible en: [http://www.journals.uchicago.edu/ t-and-c].

Rainero, L. y Rodigou, M. (2003). Indicadores urbanos de género. Instrumentos para la gobernabilidad urbana. Ponencia presentada en el 51 Congreso Internacional de Americanistas. Santiago de Chile. Disponible en: [www. redmujer.org.ar/artículos.html].

Relli, M. (2018). Política de regularización del hábitat popular urbano: provincia de Buenos Aires y partido de La Plata, 1983-2015. Tesis de doctorado no publicada. Doctorado en Geografía, Universidad Nacional de La Plata, La Plata.

Rodríguez, M. C. (2018). Género, espacialidad y urbanismo autogestionario. Algunas claves para su comprensión y debate. 3er. Congreso Internacional Vivienda y Ciudad. Debate en torno a la nueva agenda urbana. 21-22 de junio. Córdoba, Argentina.

Rodríguez, M. C. (2009). Autogestión, políticas de hábitat y transformación social. Buenos Aires: Espacio Editorial. 
Rodríguez, M. C. (2005). Como en la estrategia del caracol...ocupaciones de edificios y políticas locales del hábitat en la ciudad de Buenos Aires. Buenos Aires: El cielo por asalto.

Soto Villagrán, P. (2016). Repensar el habitat urbano desde una perspectiva de género. Debates, agendas y desafíos. Andamios, 13 (32), pp. 37-56.

Topalov, Ch. (1979). La urbanización capitalista. México: Edicol.

Winograd, M. (1988). Intercambios. Buenos Aires: Espacio.
Yujnovsky, O. (1984). Claves políticas del problema habitacional argentino 1955-1981. Buenos Aires: GEL.

Zapata, M. C. (2017). La politica habitacional porteña bajo la lupa. De los programas llave en mano a la autogestión del hábitat. Buenos Aires: Teseopress.

Zibecchi, C. (2008). Programas de transferencia de ingresos ¿Más condicionalidades y menos derechos para madres pobres? Informe de investigación. Disponible en: [http://www. derecho.uba.ar/investigacion/investigadores/ publicaciones/zibecchi-programas_de_transferencia_de_ingresos.pdf]. 